\title{
Efficacy of splint therapy for the management of temporomandibular disorders: a meta-analysis
}

\author{
Chao Zhang ${ }^{1, *}$, Jun-Yi Wu ${ }^{1,2, *}$, Dong-Lai Deng ${ }^{3}$, Bing-Yang He ${ }^{3}$, Yuan Tao ${ }^{1}$, Yu-Ming \\ $\mathrm{Niu}^{1,4}$ and Mo-Hong Deng ${ }^{5}$ \\ ${ }^{1}$ Center for Evidence-Based Medicine and Clinical Research, Taihe Hospital, Hubei University of Medicine, South Renmin \\ Road, Shiyan, China \\ ${ }^{2}$ School of Stomatology, Hubei University of Medicine, Shiyan, China \\ ${ }^{3}$ The State Key Laboratory Breeding Base of Basic Science of Stomatology \& Key Laboratory of Oral Biomedicine, Ministry of \\ Education, School \& Hospital of Stomatology, Wuhan University, Wuhan, China \\ ${ }^{4}$ Department of Stomatology, Taihe Hospital, Hubei University of Medicine, Shiyan, China \\ ${ }^{5}$ The State Key Laboratory Breeding Base of Basic Science of Stomatology \& Key Laboratory of Oral Biomedicine, Ministry of \\ Education, Department of Oral and Maxillofacial Surgery, School \& Hospital of Stomatology, Wuhan University, Wuhan, China \\ * These authors have contributed equally to this work \\ Correspondence to: Yu-Ming Niu, email: niuyuming@yeah.net
}

Mo-Hong Deng, email: dengmohong@163.com

Keywords: temporomandibular disorders; splint; maximal mouth opening; visual analogue scales of pain; meta-analysis

Received: August 24, 2016

Accepted: October 24, 2016

Published: November 03, 2016

\section{ABSTRACT}

Temporomandibular disorders (TMD) are a group of clinical problems affecting temporomandibular joint (TMJ), myofascial muscles and other related structures. Splint therapy is the most commonly used approach to treatment of TMD, but its effectiveness is remains unclear. We therefore conducted a meta-analysis to evaluate the effectiveness of splint therapy for TMD in adults. The electronic databases PubMed, EMBASE, Cochrane Library, and ClinicalTrials.gov were searched for reports published up to March 31, 2016. Thirteen eligible studies involving 538 patients were identified. The results indicated that splint therapy increased maximal mouth opening (MMO) for patients with a MMO $<45 \mathrm{~mm}$ and reduced pain intensity measured using the visual analogue scale (VAS) for patients with TMD without specific description (TMDSD). Splint therapy also reduced the frequency of painful episodes for patients with TMJ clicking. No publication bias was observed, as determined with Egger's test for all outcomes. On the basis of this evidence, we recommend the use of splints for the treatment and control of TMD in adults.

\section{INTRODUCTION}

Temporomandibular disorders (TMD) are a group of clinical problems affecting the temporomandibular joint (TMJ), myofascial muscles and other related structures [1]. There is currently no unified standard for the classification of TMD, but research diagnostic criteria for temporomandibular disorders (RDC/TMD) are the most commonly applied criteria [2]. The main signs and symptoms involve TMJ pain and clicking, myofascial or oral masticatory muscle pain, and abnormal jaw movement [3].TMD constitute a major public health problem, as they are a main source of chronic oral facial pain, interfering with daily activities [4]. These disorders are also commonly associated with other symptoms affecting the head and neck region, including headache, ear-related symptoms, cervical spine dysfunction, and altered head and cervical posture $[5,6]$. Notably, signs of TMD are detected in about $60-70 \%$ of the general population, yet only about one in four people with signs are actually aware of any symptoms [7]. The etiologies of TMD are not yet clear, but contributing factors include occlusal abnormalities, psychological stress, orthodontic treatment, microtrauma, poor health and nutrition, joint laxity and exogenous estrogen $[8,9]$. 
Table 1: Search strategy and picots criteria for the systematic review

\begin{tabular}{|l|l|}
\hline PICOS criteria & \multicolumn{1}{|l|}{} \\
\hline Population & $\begin{array}{l}\text { 1)MeSH term: (temporomandibular joint disorders) OR (temporomandibular joint disc) OR } \\
\text { (temporomandibular joint) OR (temporomandibular disorders) } \\
\text { 2)Text word: (temporomandibular joint dis*) OR (dis*, temporomandibular) OR (disc*, } \\
\text { temporomandibular joint) OR (joint dis*, temporomandibular) OR (TMJ disorders) OR (disorder, TMJ) } \\
\text { OR (disorders, TMJ) OR (TMJ dis*) OR (temporomandibular disorder*) OR TMD }\end{array}$ \\
\hline Intervention & $\begin{array}{l}\text { 3) MeSH term: splints OR (occlusal splints) } \\
\text { 4) Text word: splint* OR (splints, occlusal) OR (occlusal splint*) OR (splint, occlusal) }\end{array}$ \\
\hline Intervention & $\begin{array}{l}\text { 5) MeSH term: placebos } \\
\text { 6) Text word: placebo* OR (no treatment) OR (sham splint*) }\end{array}$ \\
\hline Outcomes & $\begin{array}{l}\text { 7) MeSH term:pain OR (pain measurement) } \\
\text { 8) Text word: (maximal mouth opening) OR (MMO) OR pain OR (pain measurement) OR (visual } \\
\text { analogue scales of pain) OR (VAS of pain) OR (healing from TMJ clicking) OR (pain relief) }\end{array}$ \\
\hline Study design & 9) MeSH term: randomized controlled trials AND controlled clinical trials \\
\hline $\begin{array}{l}\text { Search } \\
\text { combination }\end{array}$ & 1 AND 2 AND 3 AND 4 AND 5 AND 6 AND 7 AND 8 AND 9 \\
\hline Language & English \\
\hline $\begin{array}{l}\text { Electronic } \\
\text { database }\end{array}$ & $\begin{array}{l}\text { Electronic database Medline/PubMed, EMBASE, Cochrane Central Register of Controlled Trials } \\
\text { (CENTRAL) and Clinical Trails.gov }\end{array}$ \\
\hline $\begin{array}{l}\text { Focused } \\
\text { question }\end{array}$ & $\begin{array}{l}\text { Is using splint therapy helpful to improve clinical outcomes in the management of temporomandibular } \\
\text { disorders(TMD)? }\end{array}$ \\
\hline
\end{tabular}

Abbreviations:TMJ, temporomandibular joint; TMD, temporomandibular disorders; CENTRAL, Cochrane Central Register of Controlled Trials

The main treatment options for TMD include occlusal therapy [10], psychotherapy [11], physical therapy [12], medication [13], manual therapy [14], and surgery [15]. In practice, the occlusal splint is a removable appliance, usually fabricated of resin and most often designed to cover all of the occlusal and incisal surfaces of the teeth in the upper or lower jaw. Occlusal splint therapy is most commonly used clinical approach because of its ease of use, low cost, and broad indications. A previous meta-analysis addressed the effectiveness of splint therapy for TMD, but why it is effectiveremains unclear [16]. To further explore the clinical effectiveness of splint therapy in the management of TMD in adults, we performed the present meta-analysis to elucidate the functional properties of splint therapy by comparing the clinical effects reported in all relevant randomized controlled trials (RCTs) [17].

\section{RESULTS}

\section{Literature search outcome}

We identified 2062 publications in the electronic databases (Figure 1). Employing the selection criteria summarized in Materials and methods section, we obtained quantitative data for our meta-analysis after reading all titles, abstracts and full texts. Thirteen eligible studies [10, 18-27] from 11 publications were included in our final analysis.

\section{Study characteristics}

The 13 eligible studies included a total of 538 patients. The change in maximal mouth opening (MMO) was determined for 122 patients from 5 studies [10, 18, 20, 23], and the initial scope of MMO was categorized to three levels: less than $37 \mathrm{~mm}, 37 \mathrm{~mm}$ to $45 \mathrm{~mm}$, and greater than $45 \mathrm{~mm}$. The change in the amount of pain experienced, as reported using the visual analogue scale (VAS), was assessed in 285 patients from 6 studies [19-22, 25]. Three types of disorder were assessed: TMD without specific description (TMDSD) [21, 22, 25], osteoarthritis [20], and TMJ clicking [19]. The rate of healing from TMJ clicking was recorded in 170 patients from 4 studies [19, $26,27]$. The frequency of pain relief was evaluated in 112 patients from 2 studies [22, 24]. There were 5 studies [18, $20,22,23,25]$ missing standard deviations (SD), which were estimated from the P-values. Table 2 describes the clinical characteristics of patients in all 13 studies.

\section{Quality of the included studies}

The risk of bias in the included studies was strictly evaluated. Details of methodological approach are presented in Table 3. 
2062 publications obtained from electronic databases and websites (PubMed (n=972), EMBase (n=399), Cochrane Central Register of controlled Trials $(\mathrm{n}=534)$, Clinicaltrials.gov $(\mathrm{n}=157)$ )

\section{Duplicates $(\mathrm{n}=647)$}

Potential relevant publications by reading titles and abstracts $(n=1415)$

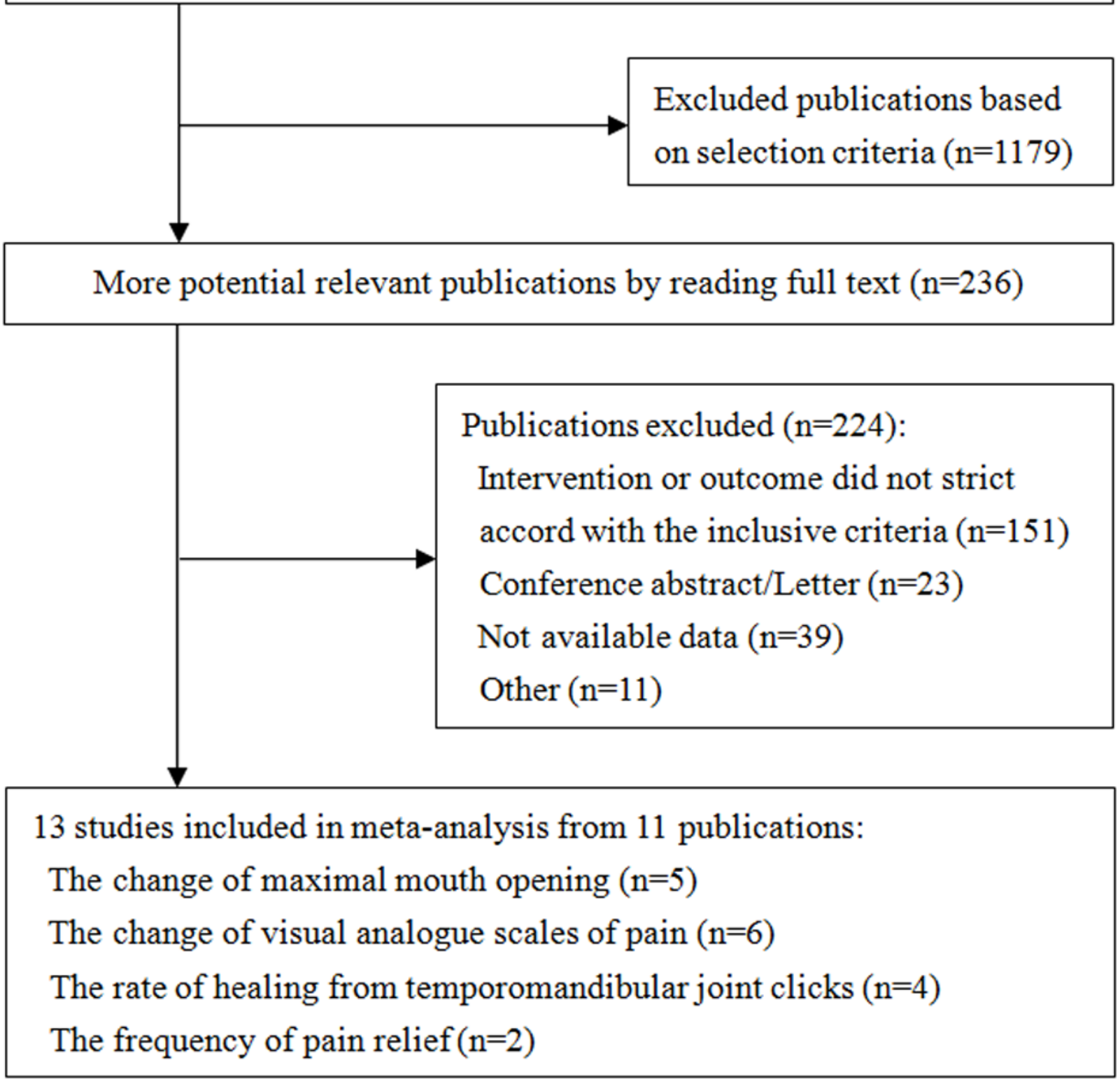

Figure 1: Summary of trial identification and selection. 
Table 2: Characteristics of the included studies

\begin{tabular}{|c|c|c|c|c|c|c|c|c|c|c|c|c|}
\hline Study & Year & Region & $\begin{array}{l}\text { Age } \\
(\text { mean } \pm \text { SD) }\end{array}$ & $\begin{array}{l}\text { Gender } \\
\text { (female \%) }\end{array}$ & Sample & $\begin{array}{l}\text { Diagnostic } \\
\text { criteria }\end{array}$ & $\begin{array}{l}\text { Classification } \\
\text { of diseases }\end{array}$ & $\begin{array}{l}\text { History } \\
\text { (month) }\end{array}$ & $\begin{array}{l}\text { Intervention } \\
\text { group }\end{array}$ & $\begin{array}{l}\text { Control } \\
\text { group }\end{array}$ & $\begin{array}{l}\text { Course } \\
\text { (month) }\end{array}$ & $\begin{array}{l}\text { Follow- } \\
\text { up } \\
\text { (month) }\end{array}$ \\
\hline Conti PC[18] & 2012 & Brazil & $38.09 / 38.14$ & $80.9 \% / 100 \%$ & $17 / 9$ & RDC/TMD & TMD & NA & splint & Self-care & NA & 3 \\
\hline Madani AS[19] & 2011 & Iran & $27.20 \pm 12.43 / 22.43 \pm 6.02$ & $75 \% / 92.86 \%$ & $20 / 14$ & $\mathrm{RDC} / \mathrm{TMD}$ & TMJ clicking & 6 & Splint & Physical & $4 / 5$ & NA \\
\hline Alpaslan C a[20] & 2008 & Turkey & $29.8 \pm 11.1 / 28.9 \pm 11.3$ & NA & $22 / 14$ & $\begin{array}{l}\text { Clinical } \\
\text { examination }\end{array}$ & Osteoarthritis & 18 & Hard splint & Arthrocentesis & NA & 6 \\
\hline Alpaslan $\mathrm{C} \mathrm{b}[20]$ & 2008 & Turkey & $31.6 \pm 10.5 / 28.9 \pm 11.3$ & NA & $9 / 14$ & $\begin{array}{l}\text { Clinical } \\
\text { examination }\end{array}$ & Osteoarthritis & 18 & Soft splint & Arthrocentesis & NA & 6 \\
\hline Al Quran FA[21] & 2006 & Jardon & $31.8 / 36$ & NA & $38 / 38$ & $\begin{array}{l}\text { Clinical } \\
\text { examination }\end{array}$ & TMD & NA & Splint & $\begin{array}{l}\text { Control } \\
\text { appliance }\end{array}$ & NA & 3 \\
\hline Ekberg E[22] & 2003 & Sweden & $31 / 28$ & $83.33 \% / 90 \%$ & $30 / 30$ & $\mathrm{RDC} / \mathrm{TMD}$ & TMD & 6 & \begin{tabular}{|l} 
Stabilization \\
splint
\end{tabular} & $\begin{array}{l}\text { Control } \\
\text { appliance }\end{array}$ & 2.5 & NA \\
\hline Maloney G[23] & 2002 & USA & NA & NA & $10 / 7$ & RDC/TMD & TMD & NA & splint & \begin{tabular}{|l} 
Control \\
appliance
\end{tabular} & NA & NA \\
\hline Ekberg E[24] & 1998 & Sweden & $13-76 / 15-72$ & $86.67 \% / 96.67 \%$ & $30 / 30$ & $\begin{array}{l}\text { Clinical } \\
\text { examination }\end{array}$ & TMD & 36 & splint & \begin{tabular}{|l} 
Control \\
appliance
\end{tabular} & 2.5 & 2.5 \\
\hline Wright EF[10] & 1995 & USA & $34 / 31$ & NA & $10 / 10$ & NA & TMD & NA & Soft splint & No treatment & 1.5 & NA \\
\hline Turk DC[25] & 1993 & USA & $35.9 \pm 9.1 / 33.1 \pm 8$ & $75 \% / 80 \%$ & $30 / 20$ & NA & TMD & 2 & splint & $\mathrm{BF} / \mathrm{SM}$ & 1.5 & 6 \\
\hline Lundh $\mathrm{H}[26]$ & 1988 & Sweden & NA & NA & $21 / 22$ & NA & $\begin{array}{l}\text { the anterior disc } \\
\text { displacement }\end{array}$ & NA & Flat splint & $\begin{array}{l}\text { Untreated } \\
\text { controls }\end{array}$ & 6 & 6 \\
\hline Lundh $\mathrm{H}$ a[27] & 1985 & Sweden & NA & NA & $24 / 23$ & NA & TMJ clicking & NA & \begin{tabular}{|l} 
Anterior \\
repositioning \\
splint
\end{tabular} & $\begin{array}{l}\text { Control } \\
\text { appliance }\end{array}$ & NA & NA \\
\hline Lundh $\mathrm{H} \mathrm{b}$ [27] & 1985 & Sweden & NA & NA & $23 / 23$ & NA & TMJ clicking & NA & Flat splint & $\begin{array}{l}\text { Control } \\
\text { appliance }\end{array}$ & NA & NA \\
\hline
\end{tabular}

Abbreviations: RDC/TMD: research diagnostic criteria for temporomandibular disorders; TMD: temporomandibular disorders; TMJ: temporomandibular joint; BF/SM: Biofeedback-assisted relaxation and stress management; NA: Not available.

Table 3: Risk of bias in the included studies

\begin{tabular}{|c|c|c|c|c|c|c|c|c|}
\hline Study & Year & \begin{tabular}{|l|} 
Random \\
sequence \\
generation
\end{tabular} & $\begin{array}{l}\text { Allocation } \\
\text { concealment }\end{array}$ & \begin{tabular}{|lr} 
Blinding of \\
participants and \\
personnel
\end{tabular} & \begin{tabular}{|l|} 
Blinding \\
of outcome \\
assessment \\
\end{tabular} & \begin{tabular}{|l|}
$\begin{array}{l}\text { Incomplete } \\
\text { outcome } \\
\text { data }\end{array}$ \\
\end{tabular} & $\begin{array}{l}\text { Selective } \\
\text { reporting }\end{array}$ & $\begin{array}{l}\text { Other } \\
\text { bias }\end{array}$ \\
\hline Conti PC[18] & 2012 & unclear & high & high & high & low & low & unclear \\
\hline Madani AS[19] & 2011 & unclear & high & high & high & low & low & high \\
\hline $\begin{array}{l}\text { Alpaslan } \quad \text { C } \\
\text { a[20] }\end{array}$ & 2008 & unclear & high & high & high & low & low & high \\
\hline $\begin{array}{ll}\text { Alpaslan } & \mathrm{C} \\
\mathrm{b}[20] & \\
\end{array}$ & 2008 & unclear & high & high & high & low & low & high \\
\hline $\begin{array}{ll}\mathrm{Al} & \text { Quran } \\
\mathrm{FA}[21] & \\
\end{array}$ & 2006 & high & high & high & high & low & low & high \\
\hline Ekberg E[22] & 2003 & low & low & high & low & low & low & unclear \\
\hline Maloney G[23] & 2002 & unclear & high & high & high & low & low & high \\
\hline Ekberg E[24] & 1998 & low & low & high & low & low & low & unclear \\
\hline Wright EF[10] & 1995 & low & high & high & high & low & low & unclear \\
\hline Turk DC[25] & 1993 & unclear & high & high & high & low & low & high \\
\hline Lundh H[26] & 1988 & unclear & high & high & high & low & low & high \\
\hline Lundh $\mathrm{H}$ a[27] & 1985 & unclear & high & high & high & low & low & high \\
\hline Lundh $\mathrm{H} \mathrm{b}$ [27] & 1985 & unclear & high & high & high & low & low & high \\
\hline
\end{tabular}

\section{Results of individual outcome variables}

\section{Changes in MMO}

Comparison of the splint therapy and control groups revealed a significant difference in the change of MMO (Figure 2) $\left(\mathrm{MD}=5.39,95 \% \mathrm{CI}[3.96,6.81], \mathrm{I}^{2}=48.9 \%\right.$, $P=0.098])$. Moreover, subgroup analysis showed that for patients with an initial $\mathrm{MMO}<37 \mathrm{~mm}(\mathrm{MD}=6.21$, $\left.95 \% \mathrm{CI}[4.50,7.92], \mathrm{I}^{2}=34.0 \%, P=0.220\right)$ or an initial $\mathrm{MMO}=37-45 \mathrm{~mm}\left(\mathrm{MD}=5.20,95 \%\right.$ CI $[1.71,8.69], \mathrm{I}^{2}$ $=$ Not available (NA), $P=\mathrm{NA}$ ), splint therapy led to a significant increase in $\mathrm{MMO}$ as compared to control. No significant difference in the change in MMO was detected for the subgroups with $\mathrm{MMO}>45 \mathrm{~mm}(\mathrm{MD}=1.57,95 \%$ CI $\left.[-2.22,5.36], \mathrm{I}^{2}=\mathrm{NA}, P=\mathrm{NA}\right)$. In addition, for the $\mathrm{MMO}<37 \mathrm{~mm}$ group, meta-regression showed there was no significant difference between the control and splint therapy groups after adjusting for differences in baseline and possible confounding factors (Table 4).

\section{Change in pain level (VAS)}

Comparison of the splint therapy and control groups also revealed a significant difference in the changes in level of perceived pain, as determined using the VAS (Figure 3) $\left(\mathrm{MD}=2.02,95 \%\right.$ CI $[1.55,2.49], \mathrm{I}^{2}=0 \%$, $P=0.558)$. Subgroup analysis showed that patients 


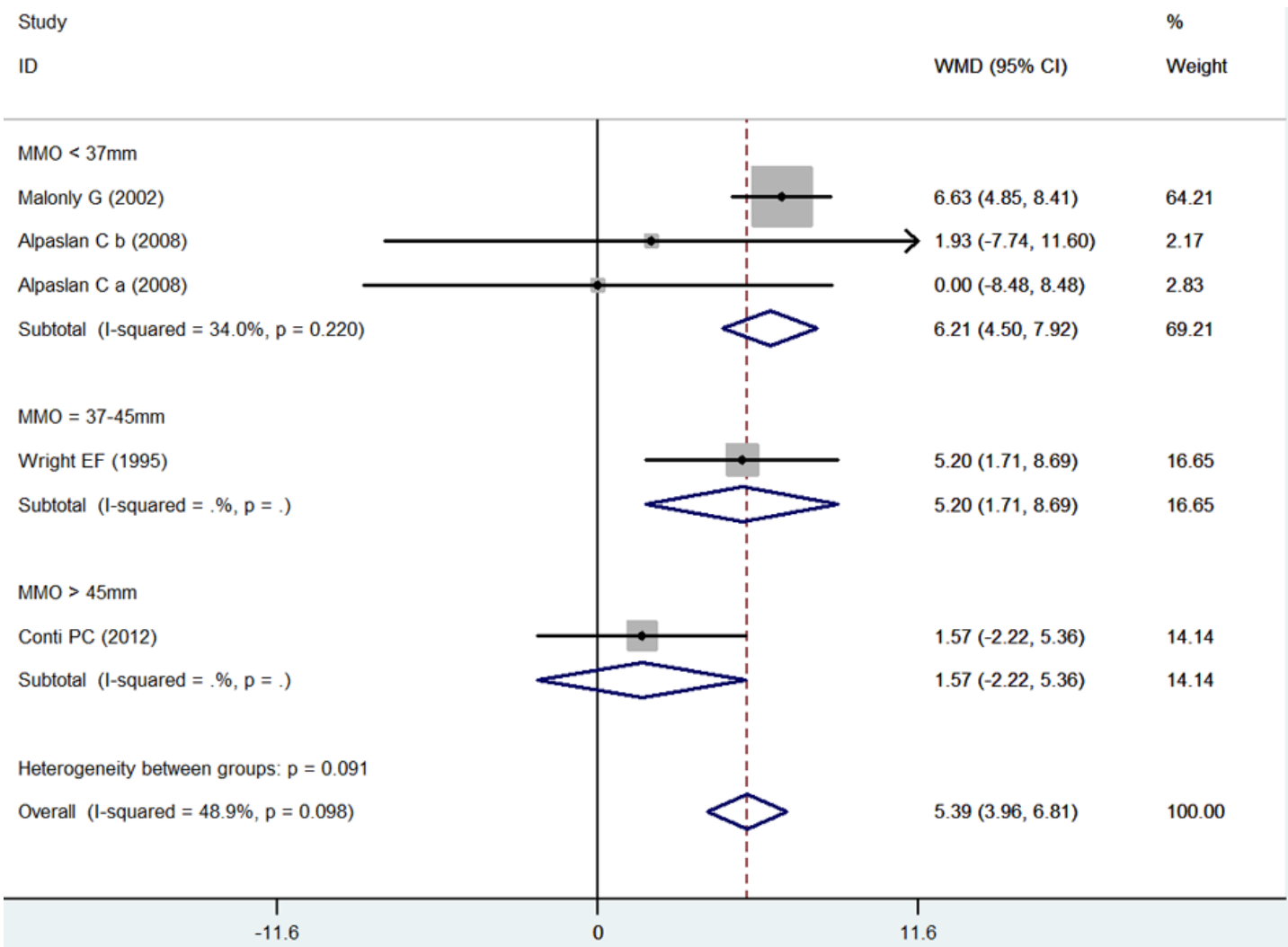

Figure 2: Forest plot of the changes in MMO.

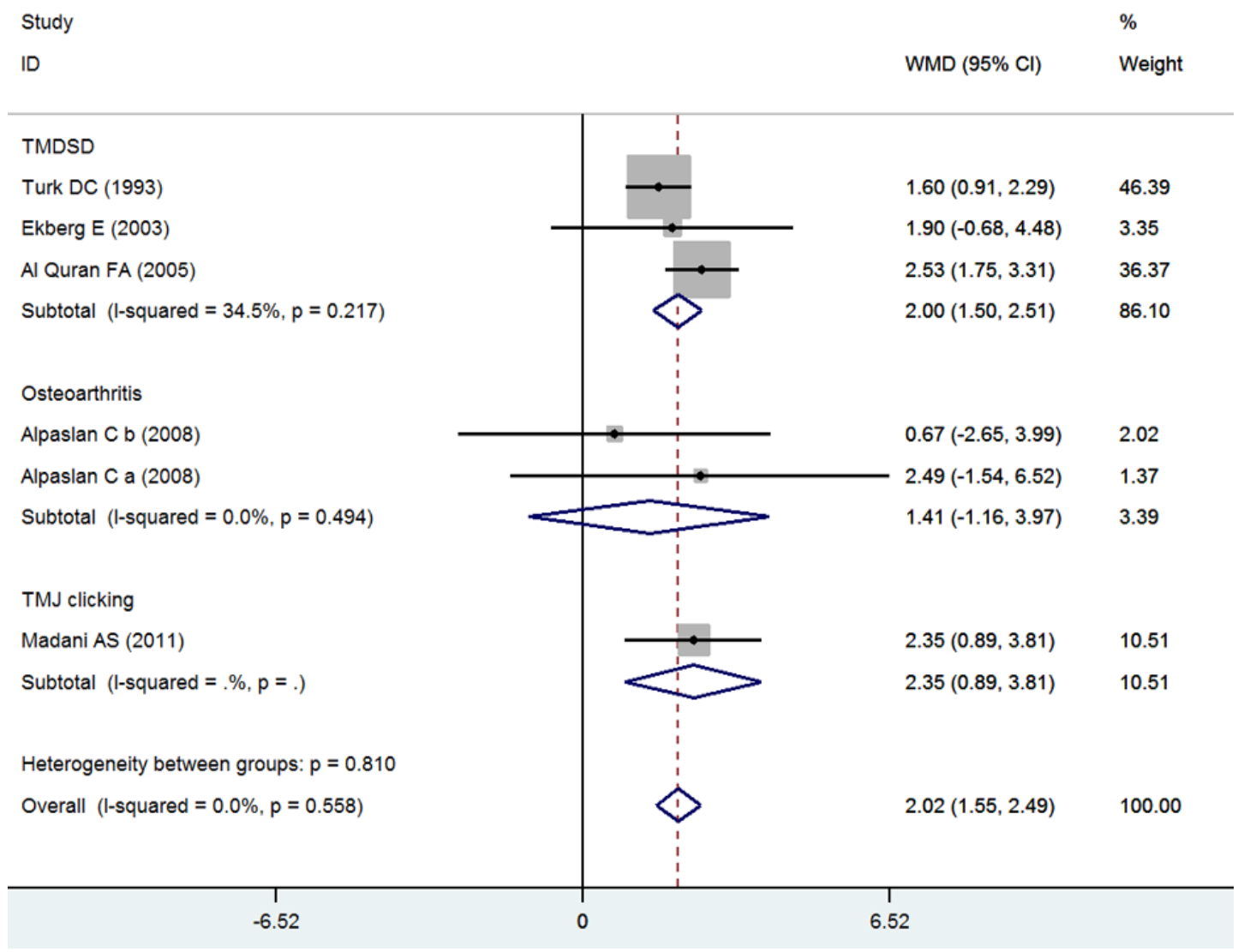

Figure 3: Forest plot of the changes in VAS for pain. 
Table 4: Meta-regression results for the main outcomes: VAS for pain and MMO $<37 \mathrm{~mm}$

\begin{tabular}{|c|c|c|c|c|c|c|}
\hline \multirow[b]{2}{*}{ Confounding factors } & \multicolumn{3}{|c|}{ MMO $<37 \mathrm{~mm}$} & \multicolumn{3}{|c|}{ VAS of pain } \\
\hline & $\begin{array}{|cc|}\text { Number } \\
\text { study }\end{array}$ & Coef $95 \%$ CI & $\boldsymbol{P}$ & $\begin{array}{c}\text { Number of } \\
\text { study }\end{array}$ & Coef $95 \%$ CI & $\boldsymbol{P}$ \\
\hline Age & 3 & $0.468(-1.941,2.878)$ & 0.703 & 6 & $-0.027(-0.215,0.162)$ & 0.782 \\
\hline Gender & 3 & NA & NA & 6 & $0.103(-0.027,0.234)$ & 0.12 \\
\hline Region ( Ref=Europe) & 0 & NA & NA & 1 & NA & NA \\
\hline North America & 1 & $\mathrm{NA}$ & NA & 1 & $-0.300(-2.969,2.369)$ & 0.826 \\
\hline Other & 2 & $-5.791(-12.409,0.826)$ & 0.086 & 4 & $0.517(-2.146,3.179)$ & 0.704 \\
\hline $\begin{array}{l}\text { Diagnostic criteria } \\
\text { (Ref=Clinical } \\
\text { examination) }\end{array}$ & 2 & NA & NA & 3 & NA & NA \\
\hline RDC & 1 & $5.791(-0.826,12.409)$ & 0.086 & 2 & $-0.193(-1.664,1.279)$ & 0.797 \\
\hline Other & 0 & $\mathrm{NA}$ & NA & 1 & $-0.834(-1.853,0.185)$ & 0.109 \\
\hline $\begin{array}{l}\text { Classification } \\
\text { of diseases } \\
\text { (Ref=Osteoarthritis) }\end{array}$ & 2 & NA & NA & 2 & NA & NA \\
\hline TMD & 1 & $5.791(-0.826,12.409)$ & 0.086 & 3 & $0.615(-2.130,3.360)$ & 0.66 \\
\hline TMJ clicking & 0 & NA & NA & 1 & $0.935(-2.196,4.066)$ & 0.558 \\
\hline Course & 3 & NA & NA & 6 & $-0.061(-0.319,0.197)$ & 0.643 \\
\hline Follow-up & 3 & $-3.217(-6.894,0.459)$ & 0.086 & 6 & $-0.318(-0.659,0.024)$ & 0.069 \\
\hline Sample & 3 & $-0.377(-0.0820,0.067)$ & 0.096 & 6 & $0.019(-0.014,0.052)$ & 0.25 \\
\hline Publish year & 3 & $-0.965(-2.068,0.138)$ & 0.086 & 6 & $0.053(-0.015,0.122)$ & 0.131 \\
\hline $\begin{array}{lr}\text { Sources } & \text { of } \\
\text { SD(Ref=Reported SD) }\end{array}$ & 1 & NA & NA & 2 & NA & NA \\
\hline $\begin{array}{l}\text { Estimate the SD from } \\
P \text { value }\end{array}$ & 2 & $2.733(-10.521,15.988)$ & 0.686 & 4 & $-0.883(-1.828,0.062)$ & 0.067 \\
\hline
\end{tabular}

Abbreviations: VAS: Visual analogue scales, MMO: Maximal mouth opening, RDC: Research diagnostic criteria, TMD: Temporomandibular disorders, TMJ: Temporomandibular joint, SD: Standard deviation, CI: Confidence interval, Coef: Coefficient, Ref: Reference, NA: Not available.

with TMDSD in the splint therapy group experienced a significant decrease in pain as compared to control (MD $\left.=2.00,95 \% \mathrm{CI}[1.50,2.51], \mathrm{I}^{2}=34.5 \%, P=0.217\right)$. This was also the case for patients with TMJ clicking $(\mathrm{MD}=$ $2.35,95 \%$ CI $\left.[0.89,3.81], \mathrm{I}^{2}=\mathrm{NA}, P=\mathrm{NA}\right)$, but not for patients with osteoarthritis (MD $=1.41,95 \%$ CI $[-1.16$, 3.97], $\left.\mathrm{I}^{2}=0 \%, P=0.494\right)$. On the other hand, metaregression revealed no significant differences in the change in VAS for pain after adjusting for baseline and possible confounding factors (Table 4).

\section{Rate of healing from TMJ clicking}

Comparison of the splint therapy and control groups using a fixed-effects model showed that there was no significant difference in the rates of healing from TMJ clicking between the two groups (Figure 4) $(\mathrm{RR}=1.17$, $95 \%$ CI $\left.[0.69,1.98], \mathrm{I}^{2}=0.0 \%, P=0.701\right)$.

\section{Frequency of pain relief}

Comparison of the splint therapy and control groups using a fixed-effects model showed that splint therapy significantly reduced the frequency of painful episodes in patients with TMJ clicking (Figure 5) $(\mathrm{RR}=1.90,95 \% \mathrm{CI}$ $\left.[1.19,3.02], \mathrm{I}^{2}=0.0 \%, P=0.442\right)$.

\section{Publication Bias}

The result of Egger's test showed there was no significant difference between both the change in MMO (Bias $=-1.915[-4.50,0.67], P=0.100)$ and the change in the VAS for pain $(\mathrm{Bias}=-0.072[-2.13,1.98], P=0.927)$.

\section{DISCUSSION}

In this meta-analysis, we evaluated 13 clinical trials that included TMD patients older than 18 years of age. We found that patients with an initial MMO less than $45 \mathrm{~mm}$ showed a statistically significant change with splint therapy, whereas patients with an initial MMO greater than $45 \mathrm{~mm}$ did not. Furthermore, subgroup analysis confirmed that splint therapy was most effective with patients exhibiting a limited ability to open their mouths. It also appears splint therapy provides significant pain relief to patients with TMDSD and TMJ clicking, but splint therapy did not reduce the pain in patients with osteoarthritis. We speculate that this is because osteoarthritis occurs after damage to the tissue has already occurred, whereas TMDSD and TMJ clicking occur in the early stage of the disease, when the splint is more able to exert a beneficial effect. In addition, although we found that splint therapy 
had no significant beneficial effect on the symptoms of TMJ clicking, the meta-analysis showed that splint therapy reduced the frequency of TMJ pain.

There are many types of splints for the treatment or control of TMD. These include the stabilization splint, soft splint, flat splint, and pivot splint [11]. Although the mechanisms of action of splints are not fully understood, Aleksandra et al [28] found that plasma levels of calcitonin gene related peptide (CGRP) were increased in TMD patients treated with an occlusal splint. CGRP is a potent neuropeptide thought to play an essential role in stretching and relaxing muscle, neurogenic vasodilatation

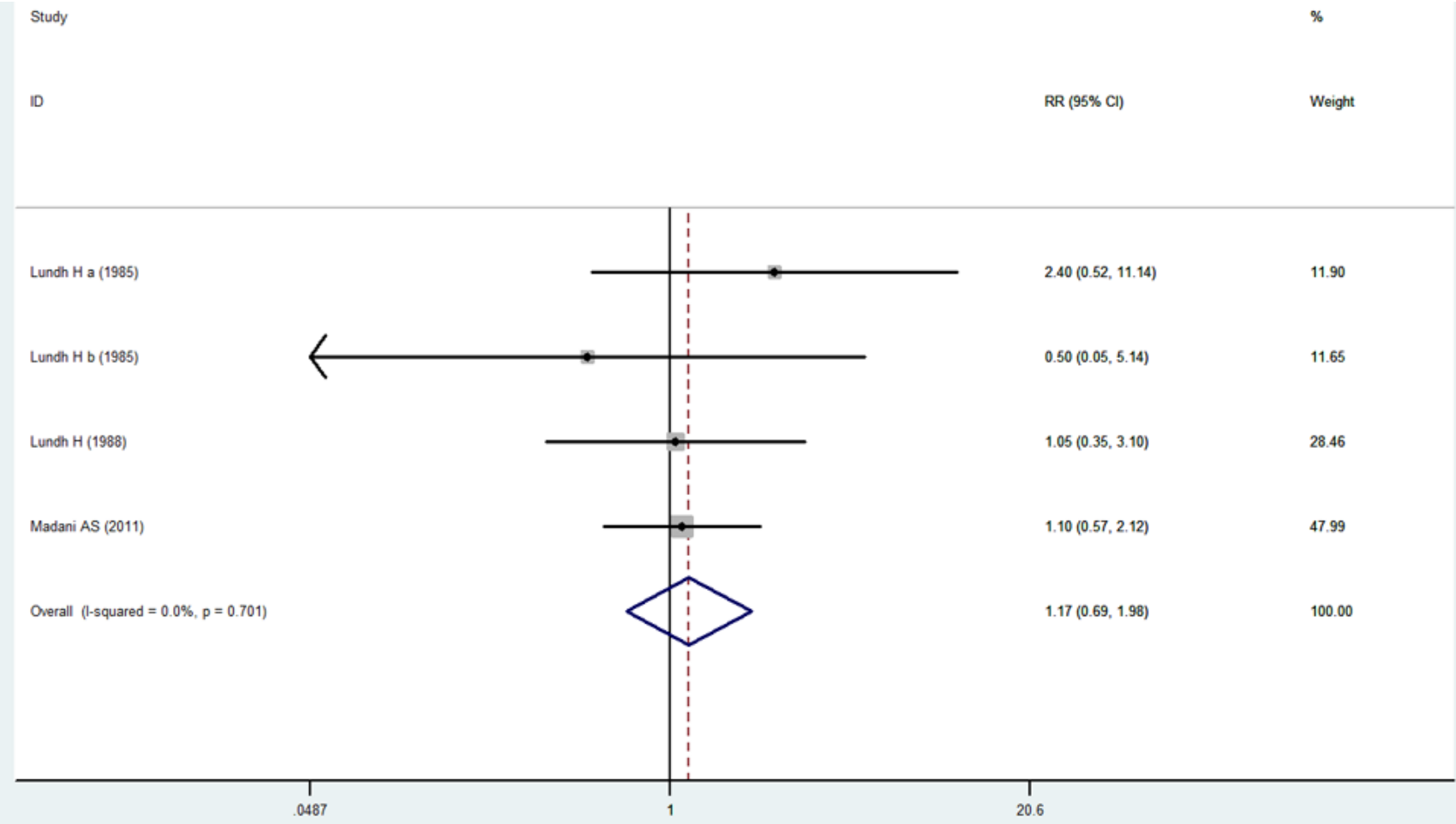

Figure 4: Forest plot of the rate of healing of TMJ clicking.

Study

ID

Overall (1-squared $=0.0 \%, p=0.442$
$\operatorname{RR}(95 \% \mathrm{Cl})$

$2 \pi(0.82,9.34)$

$1.69(1.04,274)$

$1.90(1.19,3.02)$
Weight

19.43

80.57

100.00

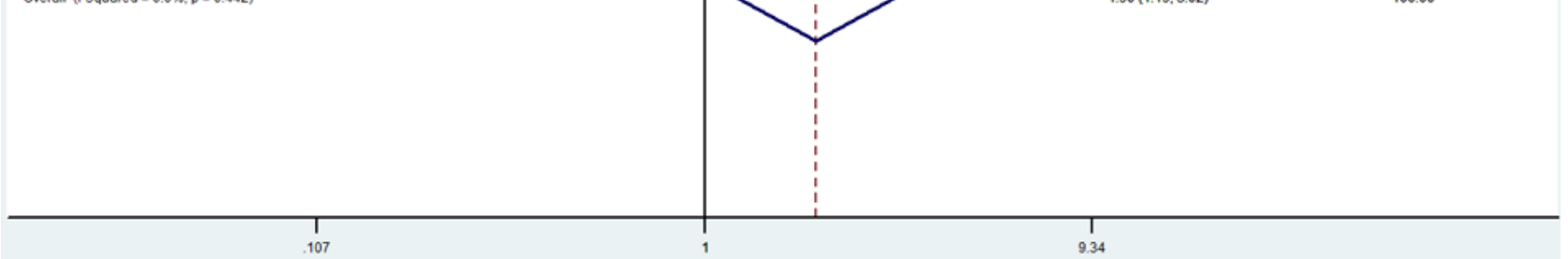

Figure 5: Forest plot of the frequency of pain relief. 
and maintaining the functional integrity of peripheral tissues [29]. We therefore suggest that the increased CGRP reflects the decreased activity muscles responsible for MMO. In addition, Glaroset al [30] proposed that splints decrease pain by preventing tooth contact and reducing muscle tension. Seligman et al [31] suggested that function occlusal relationships reflect the balance of working occlusal contacts, length and symmetry of retruded contact position-intercuspal position (RCP-ICP) slides, occlusal guidance patterns, parafunction, and dental attrition. All these interacting factors play important roles during splint therapy, which explains in part why combination therapies are more effective for the treatment of TMD [32].

To our knowledge, four meta-analyses examining effectiveness of splint therapy have been published [11, 33-35]. Two of those studies [11,34] indicated that splints reduce pain in patients with TMD. Ebrahim et al [34] included 11 studies involving 455 patients. Two outcomes, VAS for pain and the incidence of continued pain, were described without subgroup analysis. Friction et al [11] only included the rate of pain reduction among 50 patients self-reporting pain, and Al-Ani et al [35] only included pain as an outcome. MMO was not examined in any of those studies. In the present meta-analysis, we included 13 studies and used two main outcomes (VAS for pain and MMO) and two secondary outcomes (rate of healing from TMJ clicking and frequency of pain) [36]. Moreover, comprehensive subgroup analyses were conducted based on the range of initial MMO and subclasses of VAS for pain. The clinical heterogeneity was relieved, and the results were largely consistent with the experience in clinical practice [37].

There are several limitations to this study that should be addressed. First, only a few clinical trials met the inclusion and exclusion criteria. Consequently, more clinical studies will be required to confirm our results [38]. Second, some of the clinical trials had missing data on basic characteristics, possibly falsely increasing heterogeneity due to failure to perform a meta-regression for confounding factors $[39,40]$. Although we estimated the missing SD from P-values, this can lead to errors [41]. Finally, although all included studies were randomized controlled trials or parallel-group design clinical trials, we could not implement complete allocation concealment, blinding the participants and personnel to the outcome assessment [42, 43].

\section{CONCLUSIONS}

This study examined the effectiveness of splint therapy in TMD patients in a meta-analysis of published results. Our results indicate that splint therapy effectively reduces pain levels in TMDSD patients, and reduces the frequency of pain inpatients with TMJ clicking. Additionally, splint therapy increased mouth opening ability in patients with initial $\mathrm{MMO}<45 \mathrm{~mm}$. On the basis of this evidence, we recommend the use of splints for the treatment and control of TMD in adults.

\section{MATERIALS AND METHODS}

This meta-analysis was conducted according to the Preferred Reporting Items for Systematic Reviews and Meta-analyses (PRISMA) statement [44]. No ethical issues were involved in this study, and all collected data were based on published studies.

\section{Literature search strategy}

We conducted a search of four electronic databases, PubMed, EMBASE, the Cochrane Central Register of Controlled Trials and Clinical Trails.gov, up to March 31, 2016 for eligible randomized or parallel-group design clinical trials that evaluated the effectiveness of splint therapy in patients suffering from the TMD. The electronic search and the PICO (population, intervention, comparator, outcomes) strategy are shown in Table 1.

\section{Selection criteria}

All studies were selected in accordance with the following inclusion criteria: 1) RCTs; 2) included only TMD patients older than 18 years; 3) compared the effectiveness of splint therapy using controls receiving no treatment or placebo; 4) included only patients who should have been diagnosed with TMD (e.g., osteoarthritis, TMJ clicking or anterior disc displacement with or without reduction); 5) included patients who had not been administered a TMD treatment prior to the study; and 6) investigated one of the following outcomes: i) changes in MMO without support, ii) changes in VAS for pain, iii) rate of healing from TMJ clicking or iv) change in the frequency of pain from more than once a week to less than once a week. The main outcomes in this study were defined as a change of MMO and change in VAS for pain. The secondary outcomes were the rate of healing from TMJ clicking and the change in the frequency of pain.

\section{Exclusion criteria}

Studies were excluded based on the following criteria: 1) pain at rest was used as the pain score; 2) the study was a duplicate; 3 ) the data could not be extracted or obtained through contact with the author; and 4) too little information to calculate the missing SD.

\section{Data extraction}

The relevant information, including study design, patient characteristics, interventions, comparisons, and 
outcomes, were independently extracted and entered into a database by two investigators. When relevant research information was missing, particularly study design or outcome information, we contacted the original authors for clarification. The following information was extracted from each study: publication year, region, age, gender, sample, diagnostic criteria, classification of diseases, history, intervention and control groups, course, followup, and outcomes. Disagreements between the two investigators on data extraction or quality assessment were resolved by discussion. If the dispute persisted, other senior investigators were consulted to attain consensus.

\section{Quality assessment of included studies}

Two investigators independently evaluated the methodological quality of eligible trials using the Cochrane collaboration tool [38] for assessing risk of bias (random sequence generation, allocation concealment, blinding of participants and personnel, blinding of outcome assessment, incomplete outcome data, selective reporting and other sources of bias).

\section{Statistical analysis}

To describe the main outcomes based on continuous data, we used weighted mean differences (MD) [38], and $95 \%$ confidence intervals (CI). For the secondary outcomes, based on dichotomous data, we used relative risk (RR) $[38,45]$ and 95\% CI. All the outcome data were processed using STATA 14.0 software. All missing $\mathrm{SD}$ were estimated from P-values [41]. We performed a statistical test for heterogeneity [37] and adopted $\mathrm{I}^{2}>$ $50 \%$ and $\mathrm{P} \geq 0.1$ as evidence for heterogeneity [38]. If the data were homogeneous under a fixed-effects model, the initial scope of the MMO and disease classification were identified as key sources of heterogeneity in the main outcomes [37]. Heterogeneity was then dealt with using subgroups based on these modifiers. If the data were still heterogeneous, we introduced a random-effects model [37]. In addition, the baseline and possible confounding factors, including age, gender, region, diagnostic criteria, classification of diseases, course, follow-up, sample, publish year, and sources of SD, were detected using metaregression [46]. Finally, the Egger's test was employed to address quantitative detection bias [47].

\section{CONFLICTS OF INTEREST}

The authors declare no conflict of interest.

\section{Author contributors}

$\mathrm{CZ}$ and MHD had full access to all of the data in the study, and took responsibility for the integrity of the data and the accuracy of the data analysis. JYW, YMN, and CZ designed the study. MHD and YT developed and tested the data collection forms. JYW, YMN, and DLD acquired the data. $\mathrm{CZ}$ and BYH conducted the analysis and interpreted the data. JYW and YMN drafted the manuscript. All authors critically revised the manuscript. MHD and $\mathrm{CZ}$ are guarantors.

\section{REFERENCES}

1. Chen YW, Chiu YW, Chen CY and Chuang SK. Botulinum toxin therapy for temporomandibular joint disorders: a systematic review of randomized controlled trials. International journal of oral and maxillofacial surgery. 2015; 44:1018-1026.

2. Dworkin SF and LeResche L. Research diagnostic criteria for temporomandibular disorders: review, criteria, examinations and specifications, critique. Journal of craniomandibular disorders : facial \& oral pain. 1992; 6:301-355

3. Dworkin SF, Huggins KH, LeResche L, Von Korff M, Howard J, Truelove E and Sommers E. Epidemiology of signs and symptoms in temporomandibular disorders: clinical signs in cases and controls. Journal of the American Dental Association (1939). 1990; 120:273-281.

4. Armijo-Olivo S, Pitance L, Singh V, Neto F, Thie N and Michelotti A. Effectiveness of Manual Therapy and Therapeutic Exercise for Temporomandibular Disorders: Systematic Review and Meta-Analysis. Physical therapy. 2016; 96:9-25.

5. Gremillion HA. The prevalence and etiology of temporomandibular disorders and orofacial pain. Texas dental journal. 2000; 117:30-39.

6. de Wijer A, de Leeuw JR, Steenks MH and Bosman F. Temporomandibular and cervical spine disorders. Selfreported signs and symptoms. Spine. 1996; 21:1638-1646.

7. Graber, Rakosi, Petrovic. Functional analysis- examination of temporomandibular joint and condylar movement. In: Dentofacial Orthopedics with Functional Appliances. 2nd ed. St. Louis: Mosby p. 135-40,2009.

8. Sharma S, Gupta DS, Pal US and Jurel SK. Etiological factors of temporomandibular joint disorders. National journal of maxillofacial surgery. 2011; 2:116-119.

9. Gage JP. Collagen biosynthesis related to temporomandibular joint clicking in childhood. The Journal of prosthetic dentistry. 1985; 53:714-717.

10. Wright E, Anderson G and Schulte J. A randomized clinical trial of intraoral soft splints and palliative treatment for masticatory muscle pain. Journal of orofacial pain. 1995; 9:192-199. 
11. Fricton J, Look JO, Wright E, Alencar FG, Jr., Chen H, Lang M, Ouyang W and Velly AM. Systematic review and meta-analysis of randomized controlled trials evaluating intraoral orthopedic appliances for temporomandibular disorders. Journal of orofacial pain. 2010; 24:237-254.

12. Ahrari F, Madani AS, Ghafouri ZS and Tuner J. The efficacy of low-level laser therapy for the treatment of myogenous temporomandibular joint disorder. Lasers in medical science. 2014; 29:551-557.

13. Pramod GV, Shambulingappa P, Shashikanth MC and Lele S. Analgesic efficacy of diazepam and placebo in patients with temporomandibular disorders: a double blind randomized clinical trial. Indian journal of dental research. 2011; 22:404-409.

14. Tuncer AB, Ergun N, Tuncer $\mathrm{AH}$ and Karahan S. Effectiveness of manual therapy and home physical therapy in patients with temporomandibular disorders: A randomized controlled trial. Journal of bodywork and movement therapies. 2013; 17:302-308.

15. Al-Moraissi EA. Arthroscopy versus arthrocentesis in the management of internal derangement of the temporomandibular joint: a systematic review and metaanalysis. International journal of oral and maxillofacial surgery. 2015; 44:104-112.

16. Ramfjord SP and Ash MM. Reflections on the Michigan occlusal splint. Journal of oral rehabilitation. 1994; 21:491500.

17. Borenstein M, Hedges LV, Higgins JP and Rothstein HR. A basic introduction to fixed-effect and random-effects models for meta-analysis. Research synthesis methods. 2010; 1:97-111.

18. Conti PC, de Alencar EN, da Mota Correa AS, Lauris JR, Porporatti AL and Costa YM. Behavioural changes and occlusal splints are effective in the management of masticatory myofascial pain: a short-term evaluation. Journal of oral rehabilitation. 2012; 39:754-760.

19. Madani AS and Mirmortazavi A. Comparison of three treatment options for painful temporomandibular joint clicking. Journal of oral science. 2011; 53:349-354.

20. Alpaslan C, Kahraman S, Guner B and Cula S. Does the use of soft or hard splints affect the short-term outcome of temporomandibular joint arthrocentesis? International journal of oral and maxillofacial surgery. 2008; 37:424-427.

21. Al Quran FA and Kamal MS. Anterior midline point stop device (AMPS) in the treatment of myogenous TMDs: comparison with the stabilization splint and control group. Oral surgery, oral medicine, oral pathology, oral radiology, and endodontics. 2006; 101:741-747.

22. Ekberg E, Vallon D and Nilner M. The efficacy of appliance therapy in patients with temporomandibular disorders of mainly myogenous origin. A randomized, controlled, shortterm trial. Journal of orofacial pain. 2003; 17:133-139.

23. Maloney GE, Mehta N, Forgione AG, Zawawi KH, AlBadawi EA and Driscoll SE. Effect of a passive jaw motion device on pain and range of motion in TMD patients not responding to flat plane intraoral appliances. Cranio : the journal of craniomandibular practice. 2002; 20:55-66.

24. Ekberg E, Vallon D and Nilner M. Occlusal appliance therapy in patients with temporomandibular disorders: A double-blind controlled study in a short-term perspective. Acta Odontologica Scandinavica. 1998; 56:122-128.

25. Turk DC, Zaki HS and Rudy TE. Effects of intraoral appliance and biofeedback/stress management alone and in combination in treating pain and depression in patients with temporomandibular disorders. The Journal of prosthetic dentistry. 1993; 70:158-164.

26. Lundh H, Westesson PL, Jisander S and Eriksson L. Diskrepositioning onlays in the treatment of temporomandibular joint disk displacement: comparison with a flat occlusal splint and with no treatment. Oral surgery, oral medicine, and oral pathology. 1988; 66:155-162.

27. Lundh H, Westesson PL, Kopp S and Tillstrom B. Anterior repositioning splint in the treatment of temporomandibular joints with reciprocal clicking: comparison with a flat occlusal splint and an untreated control group. Oral surgery, oral medicine, and oral pathology. 1985; 60:131-136.

28. Nitecka-Buchta A, Marek B and Baron S. CGRP plasma level changes in patients with temporomandibular disorders treated with occlusal splints - a randomised clinical trial. Endokrynologia Polska. 2014; 65:217-223.

29. Grant AD, Tam CW, Lazar Z, Shih MK and Brain SD. The calcitonin gene-related peptide (CGRP) receptor antagonist BIBN4096BS blocks CGRP and adrenomedullin vasoactive responses in the microvasculature. British journal of pharmacology. 2004; 142:1091-1098.

30. Glaros AG, Owais $\mathrm{Z}$ and Lausten L. Reduction in parafunctional activity: a potential mechanism for the effectiveness of splint therapy. Journal of oral rehabilitation. 2007; 34:97-104.

31. Seligman DA and Pullinger AG. The role of functional occlusal relationships in temporomandibular disorders: a review. Journal of craniomandibular disorders : facial \& oral pain. $1991 ; 5: 265-279$.

32. Cuccia AM, Caradonna C and Caradonna D. Manual therapy of the mandibular accessory ligaments for the management of temporomandibular joint disorders. The Journal of the American Osteopathic Association. 2011; 111:102-112.

33. Fricton J. Current evidence providing clarity in management of temporomandibular disorders: summary of a systematic review of randomized clinical trials for intra-oral appliances and occlusal therapies. The journal of evidence-based dental practice. 2006; 6:48-52.

34. Ebrahim S, Montoya L, Busse JW, Carrasco-Labra A and Guyatt GH. The effectiveness of splint therapy in patients with temporomandibular disorders: a systematic review and meta-analysis. Journal of the American Dental Association (1939). 2012; 143:847-857. 
35. Al-Ani MZ, Davies SJ, Gray RJ, Sloan P and Glenny AM. Stabilisation splint therapy for temporomandibular pain dysfunction syndrome. Cochrane Database Syst Rev. 2004; :CD002778.

36. Moher D, Hopewell S, Schulz KF, Montori V, Gotzsche PC, Devereaux PJ, Elbourne D, Egger M and Altman DG. CONSORT 2010 explanation and elaboration: updated guidelines for reporting parallel group randomised trials. BMJ (Clinical research ed). 2010; 340:c869.

37. Higgins JP and Thompson SG. Quantifying heterogeneity in a meta-analysis. Statistics in medicine. 2002; 21:1539-1558.

38. Higgins J, Green S. Cochrane Handbook for Systematic Reviews of Interventions Version 5.1.0 [updated March 2011]. The Cochrane Collaboration, 2011; Available from www.cochrane-handbook.org. Accessed Oct 1, 2011.

39. Higgins JP and Thompson SG. Controlling the risk of spurious findings from meta-regression. Statistics in medicine. 2004; 23:1663-1682.

40. Thompson SG and Higgins JP. How should meta-regression analyses be undertaken and interpreted? Statistics in medicine. 2002; 21:1559-1573.

41. Furukawa TA, Barbui C, Cipriani A, Brambilla P and Watanabe N. Imputing missing standard deviations in metaanalyses can provide accurate results. Journal of clinical epidemiology. 2006; 59:7-10.
42. Pildal J, Hrobjartsson A, Jorgensen KJ, Hilden J, Altman DG and Gotzsche PC. Impact of allocation concealment on conclusions drawn from meta-analyses of randomized trials. International journal of epidemiology. 2007; 36:847-857.

43. Noseworthy JH, Ebers GC, Vandervoort MK, Farquhar RE, Yetisir E and Roberts R. The impact of blinding on the results of a randomized, placebo-controlled multiple sclerosis clinical trial. Neurology. 2001; 57:S31-35.

44. Moher D, Liberati A, Tetzlaff J and Altman DG. Preferred reporting items for systematic reviews and meta-analyses: the PRISMA statement. BMJ. 2009; 339:b2535.

45. Deeks JJ. Issues in the selection of a summary statistic for meta-analysis of clinical trials with binary outcomes. Statistics in medicine. 2002; 21:1575-1600.

46. Oxman AD and Guyatt GH. A consumer's guide to subgroup analyses. Annals of internal medicine. 1992; 116:78-84.

47. Egger M, Davey Smith G, Schneider M and Minder C. Bias in meta-analysis detected by a simple, graphical test. BMJ. 1997; 315:629-634. 